\title{
Exploration of the Motivation Factors and Self-regulation, Determinant of the Communications Strategies of the Players in a Competitive Situation (Teaching of Futsal in the School in Tunisia)
}

\author{
Kacem Nejah", Souissi Mohamed Abdelkader, Naffeti Chokri, Elloumi Ali
${ }^{1}$ State, Culture and change of society, Higher Institute of Sport and Education Physics Ksar Saïd, Manouba, Tunisia ${ }^{3}$ Educational Department of PAS, Higher Institute of Sport and education physics of Sfax, Sfax, Tunisia *Corresponding author: kacemnejah@gmail.com \\ ${ }^{2}$ Group for the study of development and social environment (GEDES), Faculty of Human and Social Science of Tunis, Tunis, Tunisia
}

\begin{abstract}
Learning is a complex process involving the interaction of many factors. The purpose of this study is to determine whether the motivational factors and learning of communications strategies are determinants of the anxiety of the players in learning situations. The subscales for motivation examined in this study of intrinsic and extrinsic orientation, the value of the task, and the control of learning determines efficacy for learning. While the subscales learning strategies are repetition, the Organization, critical thinking, self-regulation, time and management of the environment, the regulation of effort, and group learning. The study group was composed of 24 students practicing the Futsal in a cycle of learning in high school. We found motivation factors that players and learning strategies are significant predictors of their motivations. The results are useful for educators in the areas of the teaching of physical and sports activities. Thus the proposed model will become a useful reference for other investigations of factors affecting motivation and communications during the competitive situations. So learning during competitive situations causes you he anxiety among the learners?
\end{abstract}

Keywords: education, communications, motivators, learning, anxiety, role

Cite This Article: Kacem Nejah, Souissi Mohamed Abdelkader, Naffeti Chokri, and Elloumi Ali, "Exploration of the Motivation Factors and Self-regulation, Determinant of the Communications Strategies of the Players in a Competitive Situation (Teaching of Futsal in the School in Tunisia)." American Journal of Educational Research, vol. 6, no. 4 (2018): 324-328. doi: 10.12691/education-6-4-5.

\section{Introduction}

Research indicates that there are a lot of factors that affect strategies for learning [1,2] (Pintrich, 2004; Banks \& Shannon, 2007; Garcia \& Pintrich, 1996). Variables are closely related to the strategies of learning [3] (Zimmerman, 2003; 2002). However, the interdependence of these variables and their effects of causality from the other is still unclear. Much of the recent research focused on various aspects of education and studied how the motivational factors and learning strategies influence the success. However, there are very few studies on the predictors of learning behaviors of self-regulation, learning strategies, motivation factors and anxiety are all interdependent and are likely to affect the strategies of learning. It is argued that these forms represent a complex network that brings changes in the strategies of learning [1,2] (Pintrich, 2004; Garcia \& Pintrich, 1996). The objective of this study is to clarify the direction and the magnitude of the relation between these variables among players in competition by doing so, an access model to explain the relationships between the factors of motivation, and self-regulated learning strategies.

The importance of motivational factors, learning strategies and the anxiety of the situation of confrontation are correlate with the problem situation and identify the nature of communications depending on the roles and sub roles associated to issue a code from intra group relations and decipher a from codes of inter group interaction.

\subsection{Theoretical Approach}

Motivation gives the desire to perform tasks, learning new knowledge to move forward in the process of learning. Motivation is a complicated research area which is the subject of several researches in various fields, its components to order social and interactional interested many specialists. Indeed, the motivation is influenced by several factors such that factors related to the cognitive aspect, affective aspect and psychological aspects. For Williams and Burden (1997) [4], the motivation is: "a State of cognitive and emotional awakening that leads to a conscious decision to act and which causes a period of 
intellectual or physical effort, to reach a goal set in advance. In the same order of ideas Ryan and Deci (2000). [5] shows that there is a reciprocal relationship between motivation and success of the teaching-learning process. Vianin (2006) [6] confirm that the absence or weakness of motivation constitute a real obstacle to the success of the teaching-learning process. Chappaz ([7], p.40) confirms the link between success and degree of motivation, he says that "the percentages of success increase with the strength of motivation, and the influence of academic motivation is even stronger in weak subjects (more they are motivated, more they succeed in the bin” [6]. FORNER [13] (1999) confirmed the correlation between motivation and success at the baccalaureate (Vianin) [6]. In the same vision, the conclusion of the exploratory research of Martin [14]. (2005) was the following: the notes are high, over the results of the "intrinsic" motivation is high, and the notes are low, over the results of the are high [6]. The theory of self-efficacy of Bandura [8] focuses on the perception that people have of their ability to produce an effect desired in a task. In his studies, Bandura determined two types of expectations:

- Expectations of results: the belief that certain behaviors, such as train, will cause some results such as improved performance.

- Expectations of efficiency: the belief that one can achieve the behaviors necessary to produce the result.

\section{Methodology}

A questionnaire was used to collect data for this study. The questionnaire included sections on motivational factors and strategies of learning possible (Dunn, Lo, Mulvenon, \& Sutcliffe [17]. (2012).

In the questionnaire, the latent variable was measured by means of indicators observed with regard to the evidence presented in the questionnaire. The questionnaire was designed, using the answers of Likert scale containing five points of ' 1 ' to ' 5 ' neat categories are simply marked with successive integers, and the response from the players is taken as the sum of the scores of all statements. The reliability of the estimation of the emotional towards the identification of correlations were reliable as was reported coefficient alpha of 0.92

\subsection{Procedure of Data Collection}

Quantitative data was obtained from a questionnaire administered to respondents 24 .

It is the main tool used in our research. It is a way to search for the reactions of the individuals. The questionnaire contains two items the first is the impact of the practice of Futsal on the motivation of the students in a learning cycle based on measurement indicators $(2,4,5,6$, $7,8,9$, and 10). The second is oriented to the determination of obstacles if they exist by the indicators $(1,3.11)$. For example Q3) according you is that there are obstacles to the practice of futsal in the school environment. End to allow a communicability of the issues and an authenticity of the responses of the subjects concerned.

\section{Results}

The sample consisted of 24 players from a secondary team of Government of Sfax. Table 1 shows the average percentages of the frequencies of the motivational factors, to compare the motivating factors, players seem to be very compelling on the value of learning of the will, of care, of enjoyment and of talent, confidence and self-efficacy in learning. However, they do not see a lot of reward for their efforts in learning. They are also less concerned with low intellectual stimulation. They are not sure about their approaches to learning.

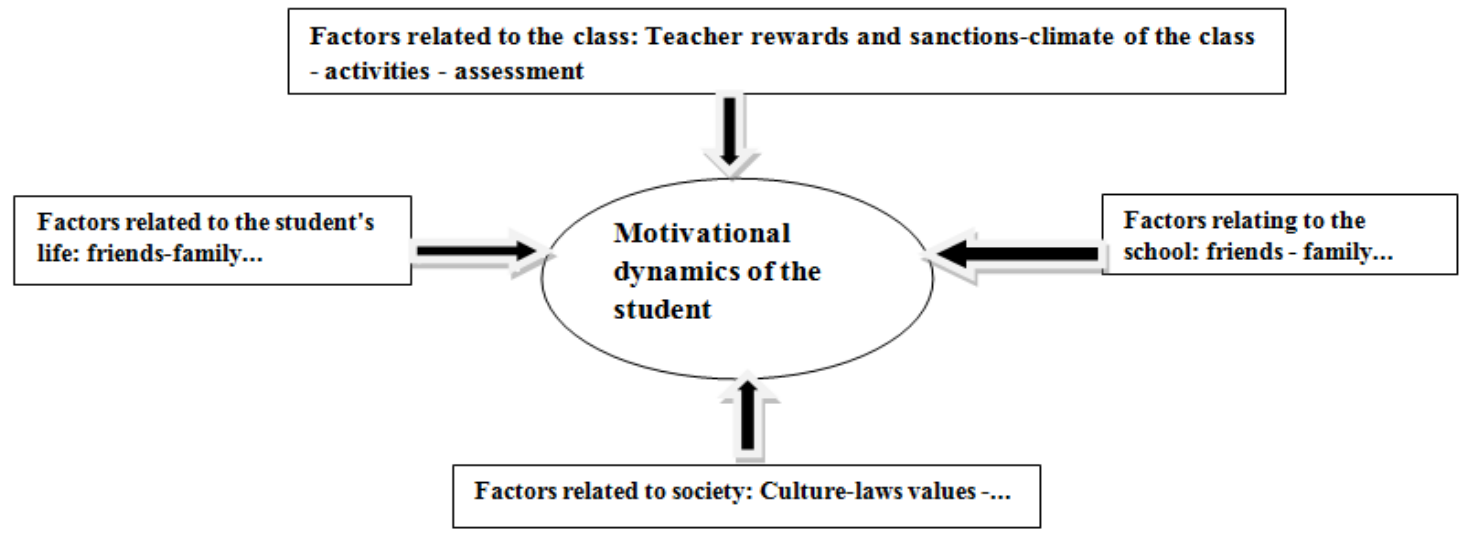

Figure 1. The factors that influence the motivational dynamics of the student Viau, A. (1994) [16].

Table 1. Averages and statistical values for three groups of Futsal in the different variables to the level of the pre-test.

\begin{tabular}{|c|c|c|c|c|c|c|}
\hline & \multicolumn{2}{|c|}{ pre test } & \multicolumn{2}{|c|}{ pre test } & \multicolumn{2}{|c|}{ pre test } \\
\hline & G1 Futsal & G 2 Futsal & G2 Futsal & G3 Futsal & G1 Futsal & G 3 Futsal \\
\hline Average & 2,900 & 2,900 & 3,600 & 3,100 & 3,300 & 2,900 \\
\hline Standard deviation & 0,738 & 0,738 & 0,516 & 0,738 & 0,675 & 0,738 \\
\hline Variation coeff & $25 \%$ & $25 \%$ & $14 \%$ & $24 \%$ & $20 \%$ & $25 \%$ \\
\hline $\mathbf{N}$ & 8 & 8 & 8 & 8 & 8 & 8 \\
\hline DDL & \multicolumn{2}{|c|}{14} & \multicolumn{2}{|c|}{14} & \multicolumn{2}{|c|}{14} \\
\hline T Student & \multicolumn{2}{|c|}{0,000000} & \multicolumn{2}{|c|}{1,783696} & \multicolumn{2}{|c|}{1,277995} \\
\hline $\mathbf{P}$ & \multicolumn{2}{|c|}{1,0000} & \multicolumn{2}{|c|}{0,0962} & \multicolumn{2}{|c|}{0,2220} \\
\hline Decision & \multicolumn{2}{|c|}{ NS } & \multicolumn{2}{|c|}{ NS } & \multicolumn{2}{|c|}{ NS } \\
\hline
\end{tabular}


We see according to the statistical data appear in the table below, the student's t values calculated at the level of the different variables of the three groups: are non-significant. Reflecting the subjects tested at the level of the three groups and in the general population are not significantly different at the level of the pre-test.

These findings are supported by the values of the coefficient of variation in the different variables used in our research.

We see from the results shown in Table 2 overall khi2 calculated at the level of different items regarding the motivation of the student during the competitive situations of confrontation over a cycle of Futsal are very significant which shows that reviews of topics question are significantly different in all of the items, where the exception is presented at the level of items 2 (a) and 5 that they contain no dissimilarity between the responses of students. However, we find that the opinions of students converged to the effect of the practice of Futsal on emotional, self-confidence and motivation justified with percentages presented respectively on the beneficial effect of the practice of Futsal.,50,0\% emotionally, 87,5\% for self-confidence, $93,8 \%$ for motivation.
Furthermore, the treatment of data concerning the items 6 and 10 that despite the short duration of the cycle through our experience, students are characterized by a significant difference between their views on the practice of Futsal outside the school context and to our company, this one does not identify the percentage higher than the average on the practice of this activity outside the co-text school with opinions ranging from $37.5 \%$ to 3 time of practice of football a week and $6.3 \%$ for once only, in sexes investigate

We can see from the results obtained from Table 3 global khi2 is significant at the level of the different items.

Which shows that reviews of the students question are significantly different in terms of the existence of obstacles justified by the precedence of the cultural and social obstacles towards a part of the confrontation between the 2 sexes during the practice of Futsal?

The study of the identification of obstacles to the practice of Futsal showed us the views of students to interrogate converge: The existence of socio - cultural barriers that affect the practice of Futsal These findings confirm this analysis phase.

Table 2. Values and meanings of the global khi2 about the motivation of the student in Futsal

\begin{tabular}{|c|c|c|c|c|c|c|c|}
\hline $\mathbf{Q}$ & Khi G & Meaning & \multicolumn{5}{|c|}{ Contingencies \% } \\
\hline 2(a) & 0,0000 & N.S & $50,0 \%$ & $50,0 \%$ & & & \\
\hline 2(b) & 45,0000 & T.S & $87,5 \%$ & $12,5 \%$ & & & \\
\hline 2(c) & 60,3813 & T.S & $93,8 \%$ & $6,3 \%$ & & & \\
\hline 4 & 10,0000 & T.S & $50,0 \%$ & $25,0 \%$ & $25,0 \%$ & & \\
\hline 5 & 4,3750 & N.S & $25,0 \%$ & $43,8 \%$ & $31,3 \%$ & & \\
\hline 6 & 17,5000 & T.S & $12,5 \%$ & $50,0 \%$ & $37,5 \%$ & & \\
\hline 7 & 48,5719 & T.S & $6,3 \%$ & $68,8 \%$ & $25,0 \%$ & & \\
\hline 8 & 106,0250 & T.S & $75,0 \%$ & $6,3 \%$ & $12,5 \%$ & $6,3 \%$ & \\
\hline 9 & 25,2031 & T.S & $0,0 \%$ & $6,3 \%$ & $25,0 \%$ & $37,5 \%$ & $31,3 \%$ \\
\hline 10 & 32,5000 & T.S & $25,0 \%$ & $62,5 \%$ & $12,5 \%$ & & \\
\hline
\end{tabular}

Table 3. Values and meanings of the global khi2 about the obstacles met by the student

\begin{tabular}{cccc}
\hline $\mathbf{Q}$ & Khi2 G & Meaning & Contingencies \\
\hline $\mathbf{1}$ & 20,0000 & T.S & $25,0 \%$ \\
$\mathbf{1 1}$ & 45,0000 & T.S & $87,5 \%$ \\
\hline
\end{tabular}

\section{The population of the pre-test study level}

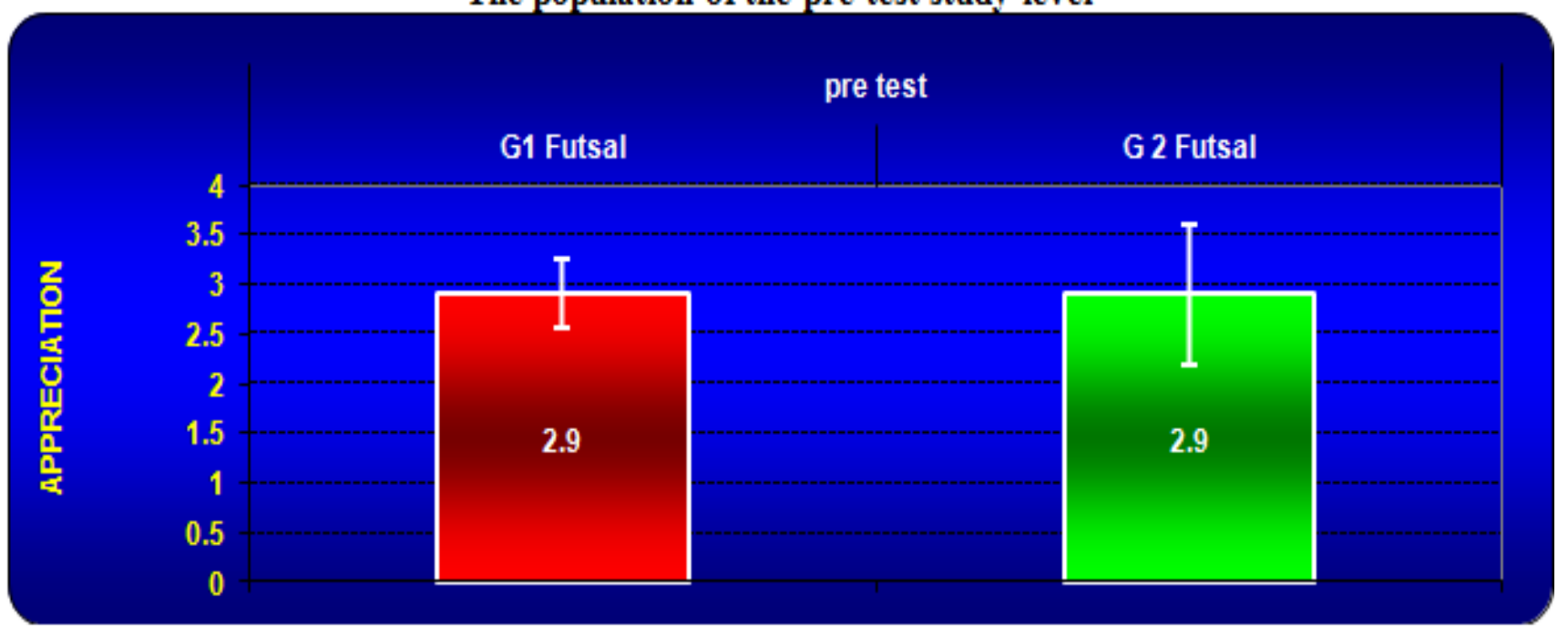

Figure 2. Comparison of two groups (1 and 2) for pre-test values 


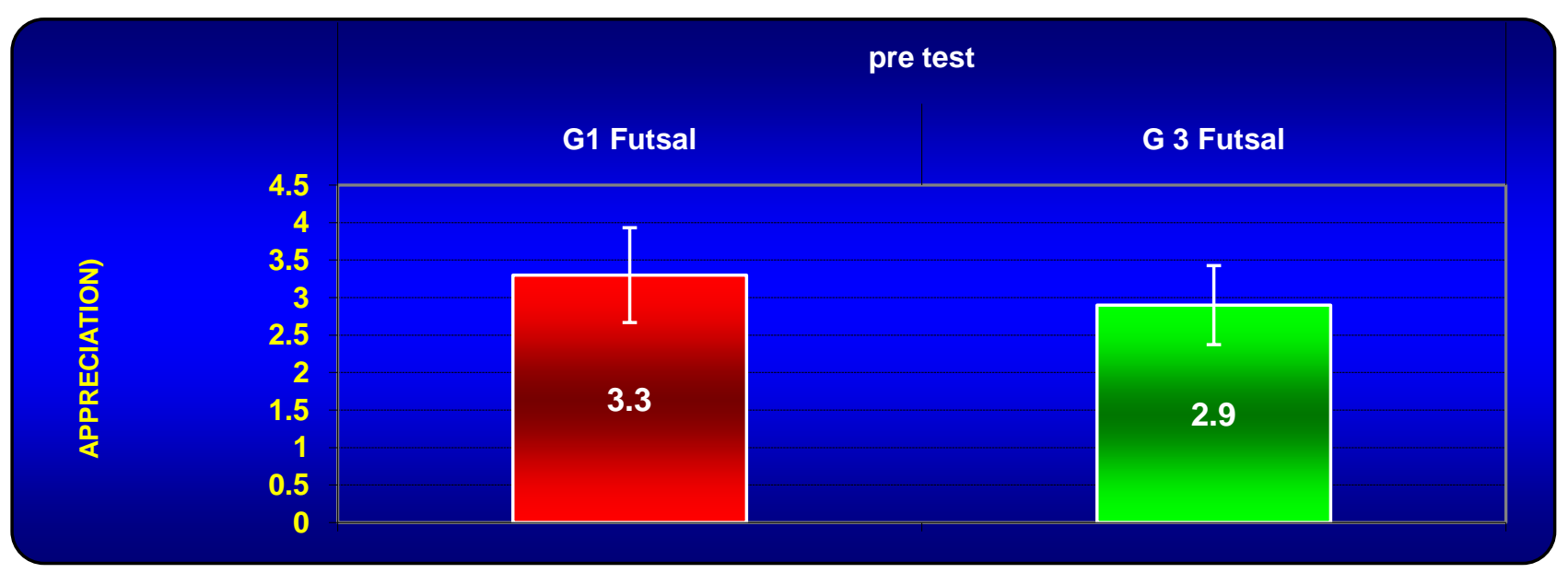

Figure 3. Comparison of two groups (1 and 3) for pre-test values

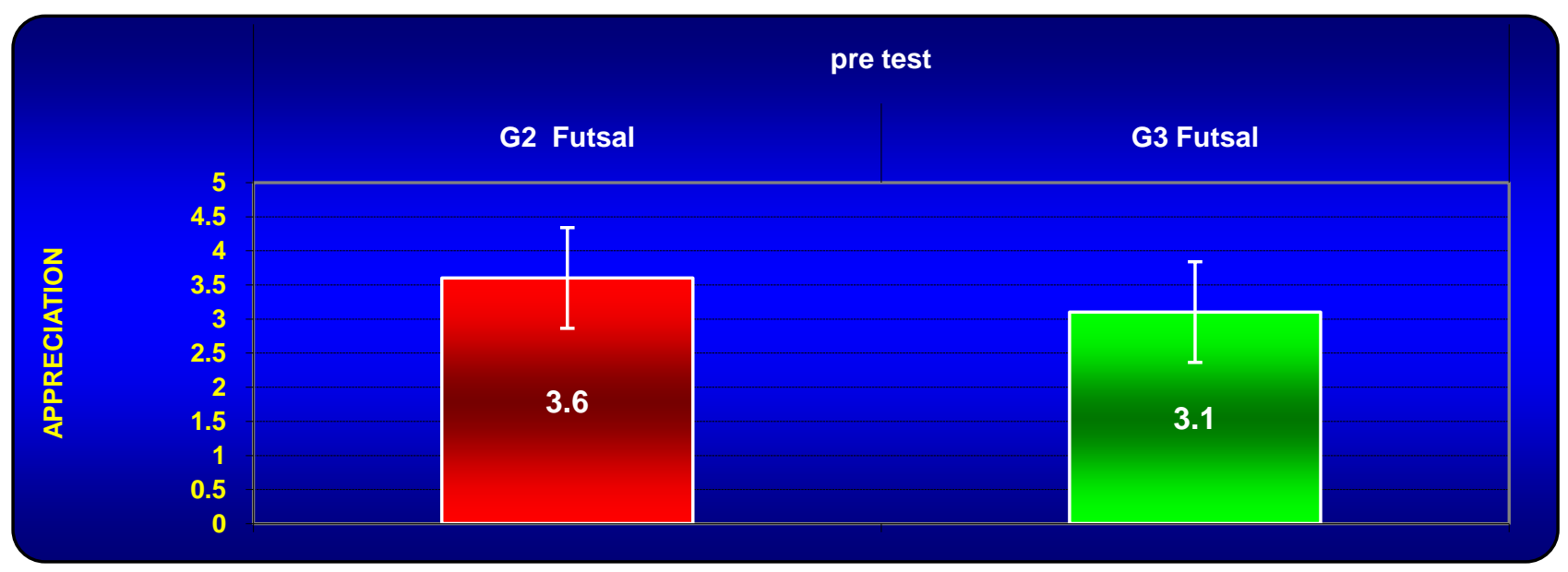

Figure 4. Comparison of two groups (2 and 3) for pre-test values

We choose to present the results achieved by content analysis and the presentation of quantitative results, the general orientation of the program of FIFA and football of the different phases of dissemination of the model teaching guide. We will not present in our study the results obtained from the study of each criterion used in this research to build the interpretation of our central subject broadcast model.

In the development of this assumption we will try to clarify how we can integrate the Futsal in secondary school and their influence on the student. The didactic transposition is a central concept of didactic work where Castillo. Martin and Albanese [15] in (2001) defined by the set of Adaptive operations thanks to they learned knowledge is transformed into knowledge to teach or learn. However, the originality of the research on the conversion lies in the study that led the most elaborate knowledge to knowledge learned by the student. Christian to able to differentiate two didactic form of transpositions: External didactic transposition which is the passage of learned knowledge to teach. Of after Amade-Escot (2004) [12]. "Analysis of the didactic transposition external reports on epistemological problem that they know that they teach? How are they with social practices of references? "

While transposing internal conducted by teachers and to transform know to teach learn teaching "observation of common practices to enter how the teaching content emerge in the context of the fact of joint action of Professor and students about the knowledge to the study objects" Amade-Escot (2004) [12]. Moreover, we tried to analyze the content of program of the Futsal through the instructions and recommendations of FIFA who directs the technical knowledge of the discipline of the Futsal that innovation. In addition we analyzed the guides and teaching the football programs in order to identify the objectives and references for the teaching of physical education and sports. Then it tried to assess the contents of the programs to know to teach through the program of the Futsal following analysis product. The Futsal for apprenticeships in EPS more use and more current. In addition it seems that this sports physical activity spreading education issues, these issues include: promote the success of students, increase their time of engine engagement and stimuli their autonomies in order to increase their motivation. However, due to the results obtained for the audits of hypothesis 3 , we can see that students prefer practice of Futsal thanks to his contribution on the emotional level, to build selfconfidence and motivation rates raise during the practice of this discipline. But the choice of the Futsal differs between places of practice exactly between the learning environment and daily life more student's vision is paradoxically remarkable especially between sex. Hence, the result show also that there are obstacles preventing us from practice of the Futsal and which can be classified into two theme the first social is marked by the look of the company with respect to this activity the second is cultural. 


\section{Discussion}

According the results of this study, the motivating factors are not significant preachers for situations of competition strong correlations between anxiety and motivator's forum considerable support for the conclusions of this study Martin and Albanese [15] (2001). The findings support the view that but if not, anxiety is a subset of the motivating factors. Almost all of the learning strategies are correlated positively to the motivating factors, thinking that is negatively correlated to the interest, intellectual learning stimulation and motivation of players factors must be increased and they should win the learning of strategies for success in competition Boshier, R. [9]. In this study the correlations between the directions of the goal of the players, and the motivational factors and learning, adopting a learning goal orientation and relative capacity are examined, including the direction of the goal translates into a general model positive motivation factors, including Adaptive of the value of the task levels, self-efficacy and anxiety, as well as cognition Bandura, A. [8], including levels higher usage of the cognitive strategy, self-regulation and academic performance. To be successful, students must determine their individual beliefs about how they will do so in future tasks, the specific objectives, proximal and diverging values, motivators and Williams and Burden learning strategies [4], such as cognitive and Meta cognitive, strategies and they should behave on a scheduled basis, based on these factors and strategies.

In addition to the high motivation factors, players must be aware of their learning, subjects must use these strategies effectively to deal with the anxiete.et should be responsible for their learning Deci and Ryan $(1985,2000)$ [10]. In relation to awareness of self-regulation of learning and learn other strategies, such as self-assessment, the Organization, the transformation, and the definition of objectives and the planning and structuring of environmental information research, giving a free consequence of repetition and memorization, seeking social assistance. For the effectiveness of learning, individuals should engage in self monitoring in order to ignore the obstacles using cognitive learning strategies and the conflicts that occur while acquiring a learning goal Zimmerman, B. J. (2004) [11].

\section{Conclusion}

In conclusion, the motivational factors and learning influence the strategies of adaptations and influence the cognitive activity in the learning process and subsequently the anxiety. Analysis of linear regression model analysis starts from a conceptual model derived specifying relationships between a set of variables.

Methods of structural equations designed to be used with substantive interests in understanding the complex patterns of interrelationships between variables. Cause and effect in the structural model are totally dependent on how the relationships are specified and results at best indicate to the plausibility of the relationships. However, the strength and the conviction with which the researcher assumes the causal link between two variables is in the analysis of the methods chosen and the theoretical justifications provided in support of the analysis. Results show that the emotional factors and strategies to act as mediator of anxiety at football competitions.

\section{References}

[1] Pintrich, 2004. A Conceptual Framework for Assessing Motivation and Self-Regulated Learning in College Students https://deepblue.lib.umich.edu/bitstream/handle/2027.42/44454/10 648_2004_Article_NY00000604.pdf?sequence $=1$.

[2] Garcia \& Pintrich, 1996. A Conceptual Framework for Assessing Motivation and Self-Regulated Learning in College Students https://deepblue.lib.umich.edu/bitstream/handle/2027.42/44454/10 648_2004_Article_NY00000604.pdf?sequence $=1$.

[3] Zimmerman, 2003; 2002 .Academic Motivation And Self-Regulated Learning In Predicting Academic Achievement In College file://C:/Users/THOCHIBA/Downloads/9190-35451-2-PB.pdf.

[4] Williams, M. \& Burden, r. (1997). Motivation in language learning: a social constructivist approach:

http://www.persee.fr/doc/apliu_02489430_1997_num_16_3_1201.

[5] Ryan and Deci (2000). Applying self-determination theory to educational practice

http://selfdeterminationtheory.org/SDT/documents/2009_Niemiec Ryan_TRE.pdf

[6] Vianin (2006). Applying self-determination theory to educational practice

http://selfdeterminationtheory.org/SDT/documents/2009_Niemiec Ryan_TRE.pdf

[7] Chappaz (1992). Impact des théories de la motivation sur l'apprentissage dans le contexte scolaire https://www.epi.asso.fr/revue/articles/a1504c.htm.

[8] Bandura, a. (1994). Self-efficacy. In, VS Ramachaudran (Ed.) https://www.uky.edu/ eushe2/Bandura/BanEncy.html

[9] Boshier, R. (1973). Educational participation and dropout: A theoretical model. Adult Education Quarterly, 23 (4), 255-282.

[10] Deci, E. L. \& Ryan, R. (1985, 2000) Intrinsic and Extrinsic Motivations: Classic Definitions and New Directions https://mmrg.pbworks.com/f/Ryan,+Deci+00.pdf.

[11] Zimmerman, B. J. (2004). Self-regulation empowerment program: A school-based program to enhance Self-regulated and selfmotivated cycles of student learning. Psychology in the Schools, 41 (5): 537-550.

[12] Amade Escot, 2004. Board training and professional development of educational advisers: cooperative and didactic knowledge search http://www.persee.fr/docAsPDF/refor_09881824_2004_num_46_1_2055.pdf.

[13] Forner (1999), MOTIVATION A learn, myth or reality, p 3

[14] Martin (2005), Motivation and engagement of boys: Evidencebased teaching practices, $\mathrm{p} 75$, https://files.eric.ed.gov/fulltext/ED536215.pdf.

[15] Martin and Albanese (2001). Impact of theories of motivation on learning in the school context.

[16] Viau, A. (1994). The motivation in school context (3e Ed.). Bruxelles De Boeck Université, https://www.epi.asso.fr/revue/articles/a1504c.htm.

[17] Dunn, Lo, Mulvenon, \& Sutcliffe (2012). Validity of the motivated strategies for learning questionnaire on a romanian sample

https://www.researchgate.net/publication/321228801_validity_of_ the_motivated_strategies_for_learning_questionnaire_on_a_roma nian_sample. 